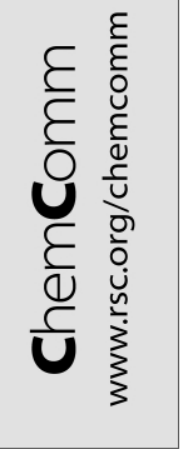

\title{
Rapid assembly of highly-functionalised difluorinated cyclooctenones via ring-closing metathesis
}

\author{
Benson M. Kariuki, ${ }^{a}$ W. Martin Owton, ${ }^{b}$ Jonathan M. Percy, ${ }^{* a} \dagger$ Stéphane Pintat, ${ }^{a \dagger}$ Clive A. Smith, ${ }^{c}$ \\ Neil S. Spencer, ${ }^{a}$ Andrew C. Thomas ${ }^{a}$ and Martin Watson ${ }^{a}$ \\ a School of Chemistry, University of Birmingham, Edgbaston, Birmingham, UK B15 $2 T T$ \\ ${ }^{b}$ Lilly Research Centre Ltd., Erl Wood Manor, Windlesham, Surrey, UK GU20 6PH \\ c GlaxoSmithKline Pharmaceuticals, New Frontiers Science Park, Third Avenue, Harlow, UK CM19 5AW
}

Received (in Cambridge, UK) 23rd October 2001, Accepted 22nd November 2001

First published as an Advance Article on the web 16th January 2002

Building block methodology from trifluoroethanol and ringclosing metathesis using a Fürstner modification of Grubbs' conditions allows the rapid synthesis of novel difluorinated cyclooctenones.

Difluoroketones are well known for their propensity to undergo the addition of even weak nucleophiles. ${ }^{1}$ This behaviour has been exploited by the medicinal chemists for the design and synthesis of protease inhibitors ${ }^{2}$ in which the hydrates (or adducts with active site nucleophiles such as serine hydroxy groups) mimic the tetrahedral intermediates traversed in peptide bond cleavage, or the transition states that lead to them. ${ }^{3}$

Well established routes allow acyclic difluoroketones to be synthesised ${ }^{4}$ but cyclic species are far less common. With the exception of Tius' concise Nazarov route to difluorocyclopentenones, ${ }^{5}$ and Portella's intramolecular aldol chemistry entered via Ruppert's reagent, ${ }^{6}$ there are few rational methods. We applied the oxy-Cope rearrangement to synthesise cyclodecenones with a highly variable fluorination pattern ${ }^{7}$ but we believe this is the only example of a rational route to medium ring fluoroketones. We noted that the ring-closing metathesis ${ }^{8}$ appeared to offer access to the eight-membered carbocyclic framework ${ }^{9}$ (still a relatively difficult pattern and of increasing interest in carbohydrate mimesis ${ }^{10}$ ) and set about exploring the utility of the RCM transformation for the synthesis of a class of novel cyclic fluoroketones.

We intercepted the metallated difluoroenol acetal $\mathbf{1}$ derived from trifluoroethanol11 with commercial aldehyde $\mathbf{2}$ and obtained the difluoroallylic alcohol 3 in good (90\%) yield after Kugelrohr distillation (Scheme 1). Allylation under phase transfer conditions $(91 \%)$ followed by [2,3]-Wittig rearrangement ${ }^{12}$ afforded ether 4 in moderate but acceptable yield (55\%). The hydroxyketone 5 was unmasked $\left(\mathrm{SOCl}_{2}-\mathrm{MeOH}, 65 \%\right)^{13}$ and subjected to RCM under standard Grubbs' conditions, returning starting material only. We reduced the hydroxyketone under the Ishihara conditions, ${ }^{14}$ obtaining a diastereoisomeric mixture of diols 6 with surprisingly low selectivity. Again the mixture failed to undergo RCM (perhaps because the catalyst decomposes in situ rapidly when two nucleophilic hydroxy groups are present ${ }^{15}$ ) but the pre-treatment of the substrate with a co-catalyst 16 allowed 5 to be transformed to a new product 8 . $\neq$ The ${ }^{19} \mathrm{~F}$ NMR of the crude product suggested a disappointing outcome but the broad ${ }^{1} \mathrm{H}$ NMR was consistent with the formation of the eight-membered ring in good yield (78\%) and the structure was confirmed by 2D NMR at $323 \mathrm{~K}$. The sequence is direct (6 steps), starts from the inexpensive trifluoroethanol and affords an wholly novel and otherwise inaccessible cyclic difluoroketone product. The ${ }^{19} \mathrm{~F}$ NMR spectrum sharpened at $223 \mathrm{~K}$ to reveal two distinct spin systems, consistent with two distinct conformations between which slow exchange was occurring. Further VT NMR $\left({ }^{1} \mathrm{H}\right)$ probing independently coalescence between the two environments for the O- $H$ and attached methine $\mathrm{C}-H$ indicated an exchange energy of $50.6 \pm$ $0.8 \mathrm{~kJ}$ mole $^{-1}$ between the two states.

$†$ Current address: Department of Chemistry, University of Leicester, University Road, Leicester, UK LE1 7RH. E-mail jmp29@le.ac.uk
A still shorter sequence would be exciting so we deployed our aldol chemistry based upon metallated difluoroenol carbamate 9 (Scheme 2). Allylic alcohol 10 was synthesised (64\%), and taken through the aldol reaction with acrolein to afford $\mathbf{1 1}$ as a mixture of syn and anti-diastereoisomers $(1: 1,64 \%)^{17}$ which could be separated almost completely by conventional column chromatography to afford syn- and anti-enriched fractions. RCM of each enriched fraction under co-catalyst conditions proceeded much more slowly than the cyclisation to $\mathbf{8}$ but starting material could be consumed after 7 days. The ${ }^{19} \mathrm{~F}$ NMR spectra of the crude products contained broad signals in the correct spectral region and the ${ }^{1} \mathrm{H}$ NMR spectra were broadened significantly but GC-MS showed the presence of two products with the correct mass with very similar retention times. To our delight, the products could be separated and then crystallised in two apparently distinct crystal forms, both of which were suitable for X-ray diffraction analysis (both species were obtained in $60 \%$ yield after crystallisation). $\$$ Triclinic crystals were revealed as the cis-diastereoisomer 12a while the transdiastereoisomer $\mathbf{1 2 b}$ crystallised in a monoclinic form. The ring conformers in the crystal structures of the two systems are very similar indeed, with the spatial location of the $N, N$-diethylcarbamoyloxy group providing the only significant difference (Fig. $1)$. Indeed, the ring conformers of both stereoisomers correspond closely to the lowest energy boat-chair conformation
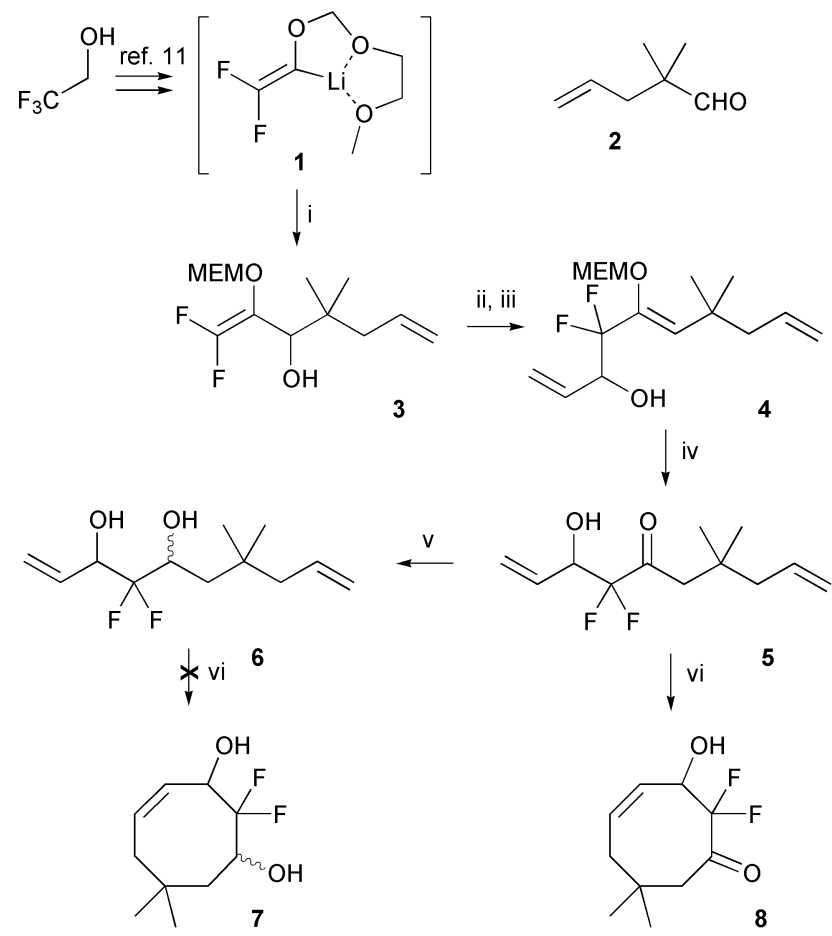

Scheme 1 Reagents and conditions: i, 2 then $\mathrm{NH}_{4} \mathrm{Cl}$; ii, allyl bromide, $\mathrm{NaOH}, \mathrm{Bu}_{4} \mathrm{NHSO}_{4}$; iii, LDA, THF, -78 to $-30{ }^{\circ} \mathrm{C}$; iv, $\mathrm{SOCl}_{2}, \mathrm{MeOH}, 0$ ${ }^{\circ} \mathrm{C}$; v, $\mathrm{NaBH}_{4}, \mathrm{MeOH}$; vi, $0.6 \mathrm{Ti}\left(\mathrm{O} i \mathrm{Pr}_{4}, 5 \mathrm{~mol} \%\right.$ Grubbs' catalyst, DCM, reflux, $24 \mathrm{~h}$ 


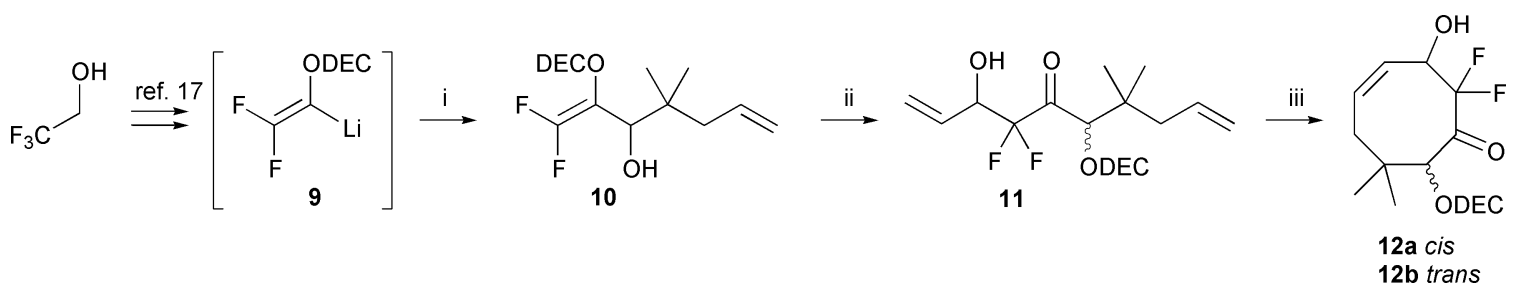

Scheme 2 Reagents and conditions: i, , $2, \mathrm{BF}_{3} \cdot \mathrm{OEt}_{2},-78$ to $-10{ }^{\circ} \mathrm{C}$; ii, n-BuLi, $\mathrm{THF}-78{ }^{\circ} \mathrm{C}$ then acrolein; iii, $0.6 \mathrm{Ti}(\mathrm{O} i \mathrm{Pr})_{4}, 5 \mathrm{~mol} \% \mathrm{Grubbs}$ ' catalyst, DCM, reflux, $166 \mathrm{~h}$.

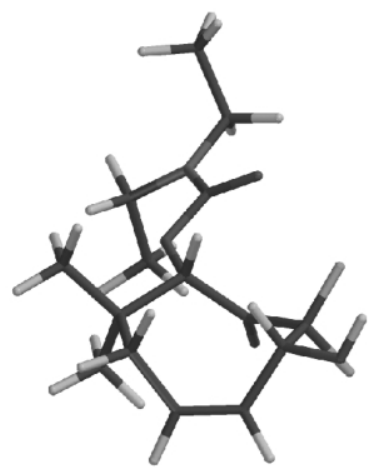

$12 \mathrm{a}$

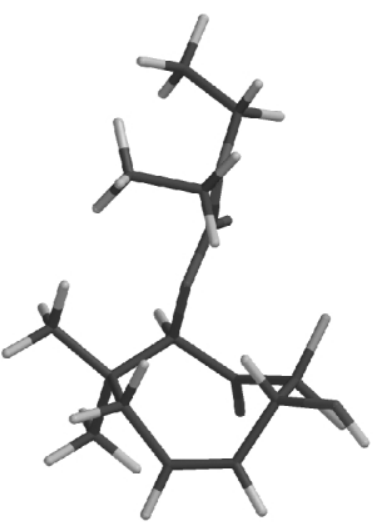

$12 b$
Fig. 1 Cis- (12a) and trans- (12b) cyclooctenone products. (a)

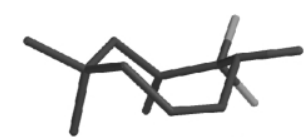

(b)

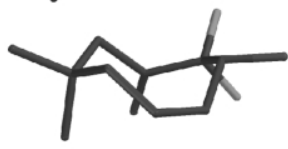

(c)

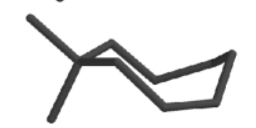

Fig. 2 Ring conformations for (a) cis- (12a), (b) trans- (12b) and (c) 4,4-dimethylcyclooct-1Z-ene (MMFF94 conformer).

(Fig. 2) assigned to cis-cyclooctene ${ }^{18}$ (which was also reproduced by an MMFF94 conformational search). ${ }^{19}$

We also noted the common alignment between the pseudoequatorial fluorine atom and the carbonyl group in the two diastereoisomers; this looks like an extremely unfavourable dipole-dipole repulsion which would probably be relieved if the carbonyl carbon were to add a nucleophile and rehybridise, thus adding an extra driving force to the addition reaction. In solution at $223 \mathrm{~K}$, the trans-isomer existed in two conformations populated similarly, whereas a single conformer dominated the ${ }^{19} \mathrm{~F}$ NMR spectrum of the cis-species. A deeper understanding of the conformational behaviour of the products is important if the idea of monosaccharide mimicry by cyclooctanic species, proposed by Sinaÿ$^{18}$ and van Boom, ${ }^{10}$ is to be realised with these compounds.

Both routes provide very direct access to structurally novel and conformationally-restricted difluoroketones which we intend to investigate more fully.

The authors wish to thank the University of Birmingham and the EPSRC (Project Grant GR/K84882) (studentship for SP), the EPSRC and Lilly Research Centre (CASE Studentship for ACT) and the University of Birmingham (Vacation studentship for M. W.).

\section{Notes and references}

$\ddagger$ Selected data for $8 . R_{\mathrm{f}}\left(30 \%\right.$ ether in light petroleum) $0.23 ; \delta_{\mathrm{H}}(400 \mathrm{MHz}$, $3,323 \mathrm{~K}) 5.86(1 \mathrm{H}, \mathrm{dq}, J=9.29,1.68 \mathrm{~Hz}), 5.60(1 \mathrm{H}, \mathrm{ddd}, J=9.29,6.85$, $3.18 \mathrm{~Hz}), 4.86-4.72(1 \mathrm{H}$, br m), $2.78(1 \mathrm{H}, \mathrm{br} \mathrm{s}), 2.52(1 \mathrm{H}, \mathrm{dd}, J=12.2,1.68$ $\mathrm{Hz}), 2.36(1 \mathrm{H}, \mathrm{d}, J=12.2 \mathrm{~Hz}), 1.99(1 \mathrm{H}, \mathrm{s}), 1.96(1 \mathrm{H}, \mathrm{s}), 1.11(3 \mathrm{H}, \mathrm{s}), 1.00$ $(3 \mathrm{H}, \mathrm{s}) ; \delta_{\mathrm{C}}\left(100 \mathrm{MHz}, \mathrm{CDCl}_{3}, 323 \mathrm{~K}\right) 198.41\left(\mathrm{t},{ }^{2} J_{\mathrm{C}-\mathrm{F}}=25.7 \mathrm{~Hz}\right), 131.84$, $129.28\left(\mathrm{~d},{ }^{3} J_{\mathrm{C}-\mathrm{F}}=3.3 \mathrm{~Hz}\right), 117.28\left(\mathrm{t},{ }^{1} J_{\mathrm{C}-\mathrm{F}}=258.2 \mathrm{~Hz}\right), 68.06\left(\mathrm{t},{ }^{2} J_{\mathrm{C}-\mathrm{F}}=\right.$ $23.1 \mathrm{~Hz}), 47.61,40.20 .37 .73,30.55,26.88 ; \delta_{\mathrm{F}}\left(282 \mathrm{MHz}, \mathrm{CDCl}_{3}, 297 \mathrm{~K}\right)$ $(-100.2)-(-118.7)(1 \mathrm{~F}$, br s $),(-121.6)-(-143.1)(1 \mathrm{~F}$, br s $) ; \delta_{\mathrm{F}}(376 \mathrm{MHz}$, $\left.\mathrm{CDCl}_{3}, 223 \mathrm{~K}\right)$ Conformer $\mathrm{A}-108.25\left(1 \mathrm{~F}, \mathrm{~d},{ }^{2} J_{\mathrm{F}-\mathrm{F}}=240.5 \mathrm{~Hz}\right),-136.07$ $\left(1 \mathrm{~F}, \mathrm{dd},{ }^{2} J_{\mathrm{F}-\mathrm{F}}=240.5 \mathrm{~Hz},{ }^{3} J_{\mathrm{H}-\mathrm{F}}=20.3 \mathrm{~Hz}\right)$; conformer B $-115.42(1 \mathrm{~F}$ $\left.\mathrm{d},{ }^{2} J_{\mathrm{F}-\mathrm{F}}=229.2 \mathrm{~Hz}\right),-129.06\left(1 \mathrm{~F}, \mathrm{dd},{ }^{2} J_{\mathrm{F}-\mathrm{F}}=240.5 \mathrm{~Hz},{ }^{3} \mathrm{~J}_{\mathrm{H}-\mathrm{F}}=26.3\right.$ $\mathrm{Hz}) ; m / z\left(\mathrm{ES}^{+}\right) 227.1\left(\mathrm{M}+\mathrm{Na}^{+}\right)$. Calc. For $\mathrm{C}_{10} \mathrm{H}_{14} \mathrm{~F}_{2} \mathrm{O}_{2} \mathrm{Na} 227.0860$. Found 227.0862 .

$\S$ Crystal data: for 12a (cis) mp 134-135 ${ }^{\circ} \mathrm{C}: \mathrm{C}_{15} \mathrm{H}_{23} \mathrm{~F}_{2} \mathrm{NO}_{4}: M=319.3$,

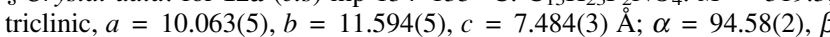
$=103.03(2), \gamma=88.35(1)^{\circ} ; U=847.7(7) \AA^{3}, T=296(2) \mathrm{K}$, space group $P-1, Z=2, \mu\left(\mathrm{Mo}_{\mathrm{K}} \mathrm{K}_{\alpha}\right) 0.104 \mathrm{~mm}^{-1}, 4660$ reflections measured, 2681 unique $\left(R_{\text {int }}=0.0445\right)$ which were used in all calculations; $R_{1}=0.058, w R_{2}$ $=0.15$. The final $w R\left(F^{2}\right)$ was 0.1904 (all data). For 12b (trans) mp 128-129 ${ }^{\circ} \mathrm{C}: \mathrm{C}_{15} \mathrm{H}_{23} \mathrm{~F}_{2} \mathrm{NO}_{4} M=319.3$, monoclinic, $a=14.912(1), b=7.5944(6)$, $c=14.8779(11) \AA, b=100.353^{\circ}$; (2) $U=1657.4(2) \AA^{3}, T=296(2) \mathrm{K}$, space group $P 2_{1} / a, Z=4, \mu\left(\mathrm{Mo}-\mathrm{K}_{\alpha}\right) 0.106 \mathrm{~mm}^{-1}$, 7335 reflections measured, 2882 unique $\left(R_{\text {int }}=0.0852\right)$ which were used in all calculations; $R_{1}=0.066, w R_{2}=0.17$. The final $w R\left(F^{2}\right)$ was 0.2034 (all data). CCDC 173277 and 173278. See http://www.rsc.org/suppdata/cc/b1/b109651f/ for crystallographic files in .cif or other electronic format.

1 M. H. Gelb, J. P. Svaren and R. H. Abeles, Biochemistry, 1985, 24, 1813.

2 For a recent example, see: M. S. Wolfe, J. Med. Chem., 2001, 44, 2039.

3 D. Schirlin, J. M. Rondeau, B. Podlogar, C. Tardif, C. Tarnus, V. VanDorsselaer and R. Farr, in Biomedical Frontiers of Fluorine Chemistry, ed. I. Ojima, J. R. McCarthy and J. T. Welch, ACS Symp. Ser., 1996, 639, 169.

4 O. Lefebvre, T. Brigaud and C. Portella, J. Org. Chem., 2001, 66, 1941.

5 P. E. Harrington and M. A. Tius, J. Org. Chem., 1999, 64, 4025.

6 O. Lefebvre, T. Brigaud and C. Portella, Tetrahedron, 1998, 54, 5939.

7 G. Dimartino, T. Gelbrich, M. B. Hursthouse, M. E. Light, J. M. Percy and N. S. Spencer, Chem. Commun., 1999, 2535.

8 A. Fürstner, Angew. Chem., Ed. Engl., 2000, 39, 3013; L. Yet, Chem. Rev., 2000, 100, 2963.

9 P. D. Boyer, I. Hanna and S. P. Nolan, J. Org. Chem., 2001, 66, 4094.

10 P. A. V. van Hooft, R. E. J. N. Litjens, G. A. van der Marel, C. A. A. van Boeckel and J. H. van Boom, Orglett, 2001, 3, 731; W. Wang, Y. Zhang, M. Sollogoub and P. Sinaÿ, Angew. Chem., Int. Ed., 2000, 39, 2466.

11 S. T. Patel, J. M. Percy and R. D. Wilkes, Tetrahedron, 1995, 51, 9201.

12 S. T. Patel, J. M. Percy and R. D. Wilkes, J. Org. Chem., 1996, 61, 166.

13 M. J. Broadhurst, S. J. Brown, J. M. Percy and M. E. Prime, J. Chem. Soc., Perkin Trans. 1, 2000, 3217.

14 M. Kuroboshi and T. Ishihara, Bull. Chem. Soc. Jpn., 1990, 63, 1185.

15 L. Hyldtoft and R. Madsen, J. Am. Chem. Soc., 2000, 122, 8444.

16 A. Fürstner and K. Langemann, J. Am. Chem. Soc., 1997, 119, 9130.

17 A. S. Balnaves, T. Gelbrich, M. B. Hursthouse, M. E. Light, M. J. Palmer and J. M. Percy, J. Chem. Soc., Perkin Trans. 1, 1999, 2525.

18 M. St. Jacques, PhD, University of California at Los Angeles, 1967.

19 Performed using MacSpartan Pro from Wavefunction, Inc., Irvine, CA. 